\title{
Heart Transplantation in the Current Era: Thinking Outside the Box of Normal Donor Criteria
}

\author{
Nicholas Hess ${ }^{1}$ and Arman Kilic ${ }^{2}$ \\ ${ }^{1}$ University of Pittsburgh Medical Center \\ ${ }^{2}$ Medical University of South Carolina
}

September 25, 2021

Heart Transplantation in the Current Era: Thinking Outside the Box of Normal Donor Criteria Nicholas R. Hess $\mathrm{MD}^{1}$, Arman Kilic $\mathrm{MD}^{2}$

${ }^{1}$ Division of Cardiac Surgery, University of Pittsburgh Medical Center, Pittsburgh, PA

${ }^{3}$ Division of Cardiac Surgery, Medical University of South Carolina, Charleston, SC

Running Title: ECD usage during OHT

Word Count: 428

Correspondence and Reprint Requests :

Arman Kilic, MD

Division of Cardiothoracic Surgery

Medical University of South Carolina

30 Courtenay Drive, MSC 295, Suite BM279

Charleston, SC 29425

Email: kilica@musc.edu

Tel: $843-876-4841$

Fax: $843-876-4866$

We are very appreciative of the thoughtful comments and insights raised by Piperata and colleagues ${ }^{1}$ into our manuscript titled "Impact of Center Donor Acceptance Patterns on Utilization of Extended-Criteria Donors and Outcomes". ${ }^{2}$ We too hope this manuscript will support the further consideration of extended-criteria donors (ECD) for heart transplantation.

Without a doubt, we are facing a shortage of available cardiac donors to meet the needs of an ever-increasing heart failure population. In the wake of an evolving candidate waitlist, with increasing age and complexity of medical comorbidity, we are also witnessing an evolution within our available donor populations. In North America and Europe, median age and medical complexity of available donors are also increasing. ${ }^{3}$ In order to meet the increasing demands for heart donations, it is important to give thorough consideration of donors outside the box of normal acceptance standards.

ECD donation has certainly been a controversial topic since its conception. As Piperata and colleagues have stated ${ }^{1,4}$, ECD donation has been previously been linked to increased risk of primary graft failure, as 
features such as increasing age and/or left ventricular hypertrophy have been associated with this outcome. ${ }^{5}$ Additionally, multiple studies have reported reduced survival with ECD donation, especially when high-risk donors are paired with high-risk recipients. ${ }^{6-8}$ However, it is important to note that these outcomes are still far better than the natural history of heart failure without transplantation.

As the heart failure population continues to grow, and the supply-demand balance continues to tip in the wrong direction, transplanting centers must start looking outside the box of normal conventions. While it is simply unethical to demand surgeons to accept unsuitable organs to keep up with a rising demand, we must therefore work towards optimization of the current donor pool. One method, as suggested by Piperata $^{4}$, may be to perform concomitant procedures such as coronary revascularization and/or valvular intervention during transplantation in order to optimize donor grafts. Another method may be to focus on the development of better diagnostic tools for centers to critically evaluate, and in some instances resuscitate, organs outside normal acceptance criteria. Though still in early phase of clinical practice, pretransplant ex vivo perfusion and evaluation of marginal hearts has shown promise. Several centers have published their results of normothermic, ex vivo perfusion of marginal hearts. In these reports, short- and mid-term outcomes have been comparable to non-ECD transplants performed at these centers ${ }^{9,10}$, all while increasing transplant volumes. ${ }^{11}$ While we cannot increase the number of donors, we can certainly take steps towards a more critical evaluation and more efficient usage of our available donor pool.

\section{Disclosures and Conflicts of Interest}

Arman Kilic, MD is a speaker and a consultant for Abiomed. He is also a speaker and a consultant for Abbot. These affiliations are not in conflict with the contents of this letter.

\section{References}

1. Piperata, Antonio Caraffa, Raphael Bifulco, Olimpia Avesani, Martina Gerosa, Gino Bottio T. Heart transplantation in the new era of extended donor criteria. J Card Surg . 2021.

2. Hess NR, Seese LM, Sultan I, Wang Y, Thoma F, Kilic A. Impact of center donor acceptance patterns on utilization of extended-criteria donors and outcomes. J Card Surg . 2021. doi:10.1111/JOCS.15902

3. Khush KK, Potena L, Cherikh WS, et al. The International Thoracic Organ Transplant Registry of the International Society for Heart and Lung Transplantation: 37th adult heart transplantation report-2020; focus on deceased donor characteristics. J Hear Lung Transplant . 2020;39(10):1003-1015. doi:10.1016/j.healun.2020.07.010

4. Piperata A, Caraffa R, Bifulco O, et al. Marginal donors and organ shortness. J Cardiovasc Med . 2021;Publish Ah. doi:10.2459/jcm.0000000000001233

5. Singh SSA, Dalzell JR, Berry C, Al-Attar N. Primary graft dysfunction after heart transplantation: a thorn amongst the roses. Heart Fail Rev . 2019;24(5):805. doi:10.1007/S10741-019-09794-1

6. Samsky M, Patel CB, Owen A, et al. Ten Year Experience with Extended Criteria Cardiac Transplantation. Circ Heart Fail . 2013;6(6):1230. doi:10.1161/CIRCHEARTFAILURE.113.000296

7. Felker GM, Milano CA, Yager JEE, et al. Outcomes with an alternate list strategy for heart transplantation. J Hear Lung Transplant . 2005;24(11):1781-1786. doi:10.1016/j.healun.2005.03.014

8. Trivedi JR, Cheng A, Ising M, Lenneman A, Birks E, Slaughter MS. Heart transplant survival based on recipient and donor risk scoring: A UNOS database analysis. ASAIO J . 2016;62(3):297-301. doi:10.1097/MAT.0000000000000337

9. Schroder JN, D'Alessandro D, Esmailian F, et al. Successful Utilization of Extended Criteria Donor (ECD) Hearts for Transplantation - Results of the OCS ${ }^{\mathrm{TM}}$ Heart EXPAND Trial to Evaluate the Effectiveness and Safety of the OCS Heart System to Preserve and Assess ECD Hearts for Transplantation. J Hear Lung Transplant . 2019;38(4):S42. doi:10.1016/J.HEALUN.2019.01.088 
10. García Sáez D, Zych B, Sabashnikov A, et al. Evaluation of the organ care system in heart transplantation with an adverse donor/recipient profile. Ann Thorac Surg . 2014;98(6):2099-2106. doi:10.1016/j.athoracsur.2014.06.098

11. Wong Y, Maddicks-Law J, Raymond P, et al. Real World Experience with Transmedics Organ Care System in Cardiac Transplantation with Donor Organs Associated with Marginal Risk Factors. J Hear Lung Transplant . 2021;40(4):S195-S196. doi:10.1016/j.healun.2021.01.569 